\title{
Evidence-Based Policymaking: What Human Service Agencies Can Learn from Implementation Science and Integrated Data Systems
}

\author{
Sharon Zanti ${ }^{1} \cdot$ M. Lori Thomas ${ }^{2} \oplus$ \\ Received: 2 May 2021 / Accepted: 8 October 2021 / Published online: 1 November 2021 \\ (c) The Author(s), under exclusive licence to Springer Nature Switzerland AG 2021
}

\begin{abstract}
The evidence-based policymaking movement compels government leaders and agencies to rely on the best available research evidence to inform policy and program decisions, yet how to do this effectively remains a challenge. This paper demonstrates how the core concepts from two emerging fields-Implementation Science (IS) and Integrated Data Systems (IDS)—can help human service agencies and their partners realize the aims of the evidence-based policymaking movement. An IS lens can help agencies address the role of context when implementing evidence-based practices, complement other quality and process improvement efforts, simultaneously study implementation and effectiveness outcomes, and guide de-implementation of ineffective policies. The IDS approach offers governance frameworks to support ethical and legal data use, provides highquality administrative data for in-house analyses, and allows for more time-sensitive analyses of pressing agency needs. Ultimately, IS and IDS can support human service agencies in more efficiently using government resources to deliver the best available programs and policies to the communities they serve. Although this paper focuses on examples within the United States context, key concepts and guidance are intended to be broadly applicable across geographies, given that IS, IDS, and the evidence-based policymaking movement are globally relevant.
\end{abstract}

Keywords Evidence-based policy · Integrated data systems · Human services · Social services · Implementation science · Housing First

\section{Introduction}

Public administration of human service agencies aims to advance social welfare through efficient, effective delivery of policies, programs, and services. Yet, the complex array of modern-day human services issues—such as the Opioid Overdose Crisis (National Institute on Drug Abuse, 2020; World Health Organization, 2020), the lack of affordable housing and chronic homelessness crisis (Baptista et al., 2017; Culhane \& Byrne, 2010; Marr, 2015; Rohe, 2017),

Sharon Zanti

szanti@upenn.edu

M. Lori Thomas

loriThomas@uncc.edu

1 Actionable Intelligence for Social Policy, University of Pennsylvania, School of Social Policy and Practice, 3701 Locust Walk, Philadelphia, PA 19104, USA

2 School of Social Work, UNC Charlotte Urban Institute/Institute for Social Capital, 9201 University City Boulevard, Charlotte, NC 28223, USA the over-institutionalization of children and youth (Chege \& Ucembe, 2020; Laklija et al., 2020; Wulczyn et al., 2015)— have not been adequately addressed on a large scale in the United States (U.S.) (Fantuzzo et al., 2017; Kettl, 2002, 2009, 2012; Lindblom \& Cohen, 1979). Out of this challenge, the movement toward evidence-based policymaking has emerged to encourage use of "the best available research and information on program results to guide decisions at all stages of the policy process and in each branch of government" (Pew-MacArthur Results First Initiative, 2014, p. 2). In the U.S. context, both the Obama and Trump presidential administrations passed legislation that requires evidencebased policymaking across federal agencies (Foundations for Evidence-Based Policymaking Act, 2018; GPRA Modernization Act, 2010). State and local government organizations in the U.S. have similarly articulated that evidence-based policymaking is a priority (National Association of Counties, 2020; State Data Sharing Initiative, 2018). On an international scale, numerous countries are grappling with how to leverage evidence-based policymaking to tackle complex social problems (Kay, 2011; Nutley et al., 2007; Sanderson, 
2002). The charge for government leaders and agencies at all levels is clear-rely on the best available data and evidence when making policy and practice decisions-but how to do this remains a challenge.

In this paper, we argue that in order to realize the aims of the evidence-based policymaking movement, human service agencies and their partners must bring together two emerging fields: Implementation Science (IS) and Integrated Data Systems (IDS). Together, the core concepts and practices from these fields can create the fertile ground from which to deliver the best available policies, programs, and services to human services clients. When rigorous research evidence goes unused by agencies, client populations are ultimately impacted by the inefficient use of government resources and lack of innovative, up-to-date services.

We begin this article with an overview of the IS and IDS fields and their applicability to public administration of human service agencies. We then describe how both IS and IDS can increase capacity for the uptake of evidence-based policies and practices (EBPs). We offer practical guidance for drawing upon IS and IDS in a human service setting. We use examples to highlight how IS and IDS can enhance evidence-based policymaking, including an extended example that applies these concepts to Housing First, an evidencebased practice and policy innovation that prioritizes housing to address homelessness, minimizes program eligibility criteria, and provides supportive services from a personcentered, harm reduction perspective. Housing First began in the U.S. in the late 1990s and has since been successfully implemented globally in several countries. We also include recommendations and resources for human service agencies looking to enhance their evidence-based policymaking. While we draw on examples and literature primarily from the U.S. context, key concepts and guidance aim to be broadly applicable across geographies in state and local agencies. We frequently and interchangeably use the terms policies, programs, services, and interventions throughout this article to broadly refer to practices that government agencies undertake in service of their client populations. The term EBPs is specifically used to refer to those policies, programs, services, and interventions that have been deemed "evidence-based."

\section{Background on Implementation Science}

The field of IS began in the 1990s in response to the welldocumented "evidence-to-practice gap" in health interventions (Dearing \& Kee, 2012). The earliest documented example of this gap dates back to James Lind, who discovered through clinical trials in 1747 that citrus could treat scurvy; however, it was nearly a half-century later until the British Navy introduced this intervention on ships (Baron,
2009). Despite its roots in health care, the IS field has since expanded to psychology, public health, education, criminal justice, child welfare, and to most other human service domains, where a similar gap persists between development of EBPs and their use in practice (Dearing \& Kee, 2012). Broadly, the goals of IS are to close this gap by studying the mechanisms through which front-line workers, administrators, institutions, and even governments are able to successfully implement EBPs that can improve outcomes (Eccles \& Mittman, 2006).

IS starts with the assumption that there is an EBP to be implemented (Lane-Fall et al., 2019). The threshold for what constitutes "evidence-based" varies by field. For instance, the Canadian Best Practices Portal distinguishes public health interventions as either promising practices, best practices, or Aboriginal "Ways Tried and True" (Public Health Agency of Canada, n.d.). The European Monitoring Centre for Drugs and Drug Addiction (n.d.) provides clear standards for evidence ratings of drug-related interventions. In the U.S., the California Evidence-Based Clearinghouse for Child Welfare (n.d.) and the federal Title IV-E Prevention Services Clearinghouse (n.d.) catalog evidence for child welfare programs. The Results First Clearinghouse Database is another commonly used tool in the U.S. for locating EBPs applicable to social policymaking and human service agencies (The Pew Charitable Trusts, 2021). With an EBP to implement, IS then aims to study the strategies that promote successful uptake of the EBP, whether carried out at the individual, organizational, or jurisdictional level. Importantly, the context where the EBP is implemented is not viewed as a hindrance, but rather as a central component that informs strategies for minimizing the evidence-topractice gap (Shea et al., 2018).

It is also important to note the difference between efficacy and effectiveness research and IS. Whereas efficacy and effectiveness examine whether policy and practice interventions achieve desired client and community outcomes (e.g., reduced homelessness, economic stability, successful family reunification, decreased opioid deaths), IS research examines outcomes like how acceptable a policy change is to agency staff, whether an employee training program or a policy mandate leads to more rapid adoption of a new program, or to what extent fidelity of an intervention model is achieved. Proctor et al. (2011) named eight types of implementation outcomes that can guide the development of IS studies-acceptability, adoption, appropriateness, feasibility, fidelity, cost, penetration, and sustainability. These implementation outcomes are critical to study given that they influence process or service outcomes (e.g., timeliness, efficiency, equity), and ultimately client outcomes (e.g., symptomology, satisfaction, function) (Proctor et al., 2011). Altogether, IS offers human service agencies a set of frameworks, theories, and models (hereafter referred to as frameworks) to guide the implementation of 
EBPs and further the study of how they are most effectively put into practice.

\section{Background on Integrated Data Systems}

Similar to IS, the newly emerging field of IDS aims to improve client outcomes and increase organizational efficiency but approaches these issues through the sharing and integration of cross-sector administrative data. Data integration is "a complex type of data sharing that involves record linkage, which refers to the joining or merging of data based on common data fields" (Hawn Nelson et al., 2020, p. 1). An IDS is a formalized effort that enables the routine sharing and reuse of administrative data with strong governance and legal agreements in place; it is also sometimes referred to as a data hub, state longitudinal data system, data collaborative, or data trust (Hawn Nelson et al., 2020). This process of sharing and reusing administrative data enables government agencies and their partners, often siloed in daily operations, to observe their overlapping client populations and more accurately understand system-level complexities (Fantuzzo \& Culhane, 2016). Thus, the IDS is more than a technology solution; it is a method that facilitates collaboration between government leaders, practitioners, researchers, and community stakeholders to better understand social problems and to develop and evaluate policy solutions (Fantuzzo \& Culhane, 2016).

Dunn (1946) initially discussed linking records of vital statistics. However, in the U.S., state-level data integration for research and policymaking did not begin until the 1970s. At that time, South Carolina constructed an IDS to better understand disease prevalence, to define populations for needs assessments, and to measure service outcomes (Kitzmiller, 2014). Since then, the state has continued to expand their use of IDS data. Currently, over 90 state and local jurisdictions, non-profits, and universities in the U.S. have developed some form of IDS that seeks to leverage their vast stores of administrative data for social policymaking (Berkowitz et al., 2020). At the global level, the International Population Data Linkage Network (IPDLN) facilitates connections between administrative data linkage centers and those who use linked data for research and policymaking. There are over 1000 members in this global network (IPDLN, n.d.). The growth in IDS on a national and international scale means greater capacity for linked administrative data to support the policymaking process.

\section{Building Agency Capacity for Evidence-Based Policymaking}

Human service agencies have much to gain by incorporating IS and IDS principles and practices into regular operations. Doing so will increase organizational capacity for the uptake of EBPs in state and local agencies. The following sections highlight the core benefits of IS and IDS that human service agencies can draw upon to enhance their evidence-based policymaking.

\section{Implementation Science and Evidence-Based Policymaking}

\section{Addressing the Role of Context in Implementation}

Context refers to "the physical, organizational, institutional, and legislative structures that enable and constrain, and resource and realize, people and procedures" (May et al., 2007 , p. 3). The success of new policies and programs depends on more than just the available research evidence; it also matters how well the program or policy is adapted to fit the local setting. This is a delicate balance between preserving the integrity of the original policy or program intervention and fitting it to a real-world context. Consider the example of wearing masks during the COVID-19 pandemic, an EBP that U.S. public health agencies in particular have been grappling with how to implement given strong divisions of public opinion (Taylor, 2020). Public health studies provide clear evidence that wearing masks can prevent the spread of COVID-19 and other infectious diseases (Centers for Disease Control \& Prevention, 2020). However, they do not delineate barriers and facilitators to mask wearing, the cost of providing masks to all patients who enter a public facility, or strategies to increase public acceptance of mask wearing in stores and restaurants compared to private social settings. IS can address these issues by studying how other important factors like the level of government (e.g., federal, state, local) where mask wearing policies are enacted, the surrounding sociopolitical context, and attitudes of public officials impact mask wearing behaviors.

The Consolidated Framework for Implementation Research (CFIR), one of the most cited IS frameworks, would be especially helpful for analyzing contextual issues that influence mask wearing in a jurisdiction (Kirk et al., 2015). The CFIR includes five constructs that influence implementation - the intervention (e.g., complexity and cost of mask wearing), outer setting (e.g., peer pressure from other jurisdictions), inner setting (e.g., culture of the jurisdiction and incentivizes for mask wearing), individuals (e.g., knowledge and beliefs of citizens in the jurisdiction), and process (e.g., influence of opinion leaders) (CFIR Research Team-Center for Clinical Management Research, 2021). This framework can facilitate the study of factors that influence uptake of mask wearing. Without such a framework, media and politicians may direct public attention toward a single factor that downplays the complexity of implementing mask wearing on a large scale. Policymakers can then 
develop strategies to increase mask wearing that draw upon the specific context.

\section{Complementing Other Quality and Process Improvement Efforts}

Quality and process improvement strategies help agencies improve their service delivery and efficiency by focusing on timely, incremental changes to process, workflow, and behavior (Koczwara et al., 2018). In contrast, IS emphasizes the use of theory, rigorous scientific methods, and the creation of generalizable knowledge that produces mediumto-long-term improvements (Koczwara et al., 2018). Ultimately, however, these fields converge in their action-oriented approaches to improving services and outcomes for clients and communities. Thus, IS can complement quality and process improvement efforts, which tend to emphasize short-term improvements, by adding conceptual frameworks and mixed methods approaches to the question of how to improve outcomes over the long term using the best available evidence.

Consider a child care licensing agency that seeks to increase the number of facilities that get licensed. These agencies issue licenses to child care facilities that meet certain quality standards, often based on evidence-based public health and early childhood guidelines (Childcare.gov, n.d.). A quality and process improvement approach might employ "Lean" and "Six Sigma" frameworks that streamline paperwork requirements for providers, allow initial application submission online instead of via mail, and reduce the number of licensing staff needed to conduct facility reviews (Antony, 2011). With the addition of IS frameworks, however, these strategies could be embedded in a larger effort to understand what works for increasing and sustaining child care licensure over the long term. The Exploration, Preparation, Implementation, Sustainment (EPIS) framework includes four phases that could guide an implementation study in this example - exploration (e.g., investigating needs and characteristics of facilities that influence their pursuit of licensure), preparation (e.g., identifying barriers and facilitators to certain types of facilities applying for licensure), implementation (e.g., enacting quality and process improvement and/or other strategies based on insights surfaced in exploration and preparation), and sustainment (e.g., adapting strategies from the implementation phase to be feasible and realistic for the licensing agency) (Aarons et al., 2011; Moullin et al., 2019).

\section{Furthering Evidence on Policy Effectiveness and Implementation}

There is rarely a saturation point at which policies and practices enacted by human service agencies no longer benefit from additional effectiveness studies. Whether improving the strength of evidence, testing interventions on new subpopulations, or satisfying stakeholder expectations to continue demonstrating outcomes, effectiveness research is often ongoing. However, at some point evidence generation can delay the delivery of better services above and beyond the best interest of the target population. The field of IS addresses this tension through effectiveness-implementation hybrid trials, which seek to narrow the evidence-to-practice gap by simultaneously studying effectiveness and implementation (Curran et al., 2012). There are three types of hybrid trials-Type 1 trials primarily test the effects of an intervention while also gathering data about implementation, Type 2 trials give equal weight to studying effectiveness and implementation, and Type 3 trials primarily test an implementation strategy while also studying effectiveness (Curran et al., 2012).

As an example, Kirchner et al. (2014) conducted a quasiexperimental Type 3 hybrid trial with the U.S. Department of Veterans Affairs (VA) that tested an implementation facilitation strategy for an integrated primary care and mental health intervention while also evaluating clinical outcomes of those who received the intervention. The strategy, developed in partnership with regional VA leaders, included a team of facilitators to support staff across seven intervention sites on implementation and tailoring of the intervention, provide ongoing performance monitoring and feedback, engage local change agents, and market the intervention. An evaluation based on the Reach, Effectiveness, Adoption, Implementation, and Maintenance (RE-AIM) framework showed that this multifaceted strategy increased reach and adoption of the integrated primary care and mental health intervention, which ultimately led to improved patient access to mental health care (Glasgow et al., 1999). Specifically, patients at intervention sites (i.e., those with the implementation facilitation strategy) had nine times higher odds of accessing the integrated primary care and mental health intervention (reach) and providers at intervention sites were seven times more likely to refer patients to the integrated primary care and mental health intervention (adoption). There were no significant differences between patients at intervention sites and non-intervention sites in terms of their odds of getting referred to specialty mental health clinics (effectiveness). Hybrid trials like this allow agencies to continue to study policy effectiveness while also uncovering the mechanisms that facilitate uptake of EBPs so as to get clients effective programs faster and in ways that can be successfully implemented.

When discussing hybrid trials, it is important to note that the "gold standard" randomized controlled trial may not always be prudent or feasible to undertake in a human service setting (Fives et al. 2015). For example, ethical concerns may be raised around withholding interventions from 
those randomly assigned to a control group while experimental groups receive services. This is especially important to consider when client health and safety are at stake, such as in substance use, mental health, or child maltreatment interventions. In these instances, hybrid trials with quasiexperimental designs may be more appropriate, as demonstrated in the above example.

\section{Guiding Systematic De-implementation of Policies and Programs}

Sometimes evidence-based policymaking involves de-implementing practices that are ineffective, unproven, harmful, overused, inappropriate, and/or low-value (Norton et al. 2019). De-implementation is a unique subset within the IS field that studies how to systematically reduce or stop these types of practices. There are four key types of de-implementation: (1) removing a practice entirely, (2) replacing the practice with a more effective intervention, (3) reducing the frequency or intensity of use, and (4) restricting the setting or target population for the intervention (Norton et al. 2019).

De-implementation presents challenges, particularly for large agencies where practices are entrenched in the fabric of daily operations. Clients or service recipients may also be resistant to policies or interventions being removed or scaled back. Thus, Prusaczyk et al. (2020) articulate the importance of considering cultural and historical importance of the practice as part of the de-implementation process. The over-prescription of antibiotics provides a relevant example, where the risk to individuals of receiving unnecessary antibiotics are relatively low compared to the populationlevel risk of increasing development of antibiotic-resistant bacteria (Prusaczyk et al., 2020). Therefore, even when public health agencies recommend decreasing unnecessary antibiotic prescriptions, doctors may still encounter patients who expect to receive antibiotics and request them despite explanations of why they may be unnecessary and potentially harmful. Antibiotics were heralded as a panacea when their large-scale commercial production began around World War II and their discovery revolutionized the medical field (American Chemical Society International Historic Chemical Landmarks, n.d.). This history is important for understanding how widespread use of antibiotics has led to a culture where patients are accustomed to readily receiving antibiotics in primary care settings and may resist the idea that the drug could be damaging on a societal level.

De-implementation in human service settings has not been widely researched, though there are numerous practices ripe for de-implementation (McKay et al., 2018). Drug Abuse Resistance Education (D.A.R.E.) is frequently cited as an intervention known to be ineffective at its intended aims of reducing adolescent drug use, yet school districts in every state still use this program (D.A.R.E. America, 2021).
McKay et al. (2018) suggest that D.A.R.E. and other interventions identified as ineffective, inefficient, or unnecessary could be successfully de-implemented using a four-step process-selecting an intervention for de-implementation, assessing the de-implementation context, carrying out strategies to de-implement, and evaluating de-implementation outcomes. Existing IS frameworks are available to support each of these steps. For example, when assessing context, the EPIS framework, CFIR, and De-Adoption framework could all support the study of contextual factors that influence de-implementation strategies (McKay et al., 2018). In the EPIS framework, historical and cultural considerations, like inter-organizational environment and networks and client characteristics, are seen as part of the outer context that influences implementation of an EBP (Moullin et al., 2019). The CFIR similarly encourages consideration of the outer setting-including external policies and incentives and peer pressure from competing organizations-when assessing the context surrounding de-implementation (CFIR Research Team-Center for Clinical Management Research, 2021).

\section{Integrated Data Systems and Evidence-Based Policymaking}

\section{Facilitating Governance Processes for Ethical, Legal Data Access and Use}

Administrative data are an enticing source for producing research evidence and insights, but it cannot be ethically and legally used without strong governance in place. The IDS approach encourages stakeholder engagement in the development of a governance process that meets the needs of the local context (Gibbs et al., 2017). For example, the Institute for Social Capital (ISC) - a community IDS housed at the University of North Carolina (UNC) Charlotte Urban Institute-was founded with a collaborative governance model, where government, non-profit, and university partners each have a role in data governance and oversight (Allison-Jacobs, 2018). However, over time ISC recognized the importance of moving beyond just organizational representation and the IDS is now building a process to include people represented within administrative data in the governance process, particularly those disproportionately represented. The board members and staff initiated an intentional planning process in order to prevent tokenized representation and develop, with community stakeholders, specific mechanisms that build representation into the organization. The non-profit organization that guides ISC is currently in the process of adding a Community Data Advisory Committee, which will be integrated into the board governance structure and include community stakeholders who are overrepresented within data held by ISC. 
Governance is a crucial component for sharing and integrating cross-sector data as it establishes an ongoing process for secure data access, linkage, and analysis. An IDS can facilitate community engagement by building it into routine governance structures. Without governance, agencies rely on single-use data sharing agreements that are often inefficient, legally and administratively cumbersome, and not grounded in democratic, community-engaged processes (Gibbs et al., 2017). For instance, if a child welfare agency wants to understand housing instability among youth who "age out" of the foster care system, they might request access to Homeless Management Information System (HMIS) data, which could take months or even years to negotiate for a single project. When more data partners are involved or the complexity and sensitivity of the requested data increases, the timeline for legal data sharing negotiations only increases. The difficulty of recreating this process for each individual project can discourage cross-agency data sharing. However, establishing an IDS with a legally vetted data governance process can not only increase efficiency, but also foster collaboration across agencies and community partners to support evidence-based policymaking.

Compared to mere technology solutions for joining together administrative datasets, the IDS approach underscores the relational aspect of data sharing and integration. Though technical data integration challenges arise with any IDS effort (e.g., selecting an optimal database type and structure, marrying legacy databases with new software, implementing privacy preservation techniques), the definition of these challenges and their range of solutions tend to be more readily agreed upon by IDS stakeholders (National Implementation Research Network [NIRN], n.d.). However, more adaptive challenges abound-that is, complex challenges requiring adaptive leadership to engage stakeholders and build consensus on the nature of the challenge and how to address it-when bringing together diverse stakeholders to build data integration capacity (NIRN, n.d.). Through governance processes, an IDS can address adaptive challenges by facilitating a "community of people involved in the social problem-solving process engaging in bidirectional dialogue that converts data into actionable intelligence, uses actionable intelligence to propel decision making, analyzes and reflects on the success of their choices, and refines and revises operations accordingly" (Fantuzzo et al., 2017, p. $10)$.

\section{Providing Relevant, High-Quality Data for Efficient Analysis}

Increasing evidence-based policymaking hinges on having access to the best available data and research evidence, which is often generated in unaffiliated academic settings rather than within agencies themselves. However, human service agencies are replete with potentially relevant administrative data that are collected throughout the course of regular operations. With the proper governance processes in place, these data can be ethically reused and linked at the individual level across multiple programs and/or agencies to provide a holistic, longitudinal view of clients, families, and communities served (Hawn Nelson et al., 2020). In this way, an IDS also becomes an essential Decision Support Data System for implementation projects (NIRN, 2021).

Furthermore, housing data within a government IDS or a non-profit or university IDS that closely collaborates with its government depositors builds capacity for human service agencies to conduct onsite or prioritized analyses that are directly applicable to their most pressing policy needs (Fantuzzo et al., 2017). For instance, a public benefits agency may need to understand how many clients will experience a "cliff effect" (i.e., a drop-off in benefits) in one program if a new policy increases food assistance benefits. An IDS can provide the most applicable data to facilitate this analysis in-house or as a part of an ongoing partnership rather than contracting with an unrelated third party to collect original data, which delays time-sensitive insights for the policymaking process and comes with privacy and security risks. It is important to note that data relevancy and quality vary across administrative datasets, but agency staff and regular data partners are often better equipped than unaffiliated outside researchers to uncover and address concerns around missing data, data entry consistency, data documentation, and other common issues when reusing administrative data (Hawn Nelson et al., 2020). Therefore, the IDS approach leverages agency and partner strengths to build internal capacity for analyzing their own data.

\section{Efficiently Addressing Pressing Research, Evaluation, and Planning Needs}

When relevant, high-quality datasets are made accessible within and between agencies, they can be linked across programs to reduce the time, funding, and energy that would typically be required for original data collection and linkage. Furthermore, the use of IDS can reconcile common issues in survey research, such as low response rates and inadequate sample sizes and comparison groups, as administrative data collection routinely captures population-level data (Hawn Nelson et al., 2020). For instance, an evaluation of a city's youth employment program can leverage administrative data to compare outcomes of those who participated in the program to outcomes of the city's broader youth population or to youth who participated in similar programs with different implementation strategies. Rapid evaluations that use embedded randomized controlled trial (RCT) or quasiexperimental designs also become more plausible with an existing IDS infrastructure, thus saving substantial time and 
cost—which can be repurposed for other important agency functions-compared to traditional causal research studies.

As another example, the State of South Carolina in the U.S. leveraged their IDS capacity to evaluate a pilot psychiatric telehealth initiative that aimed to address the shortage of rural mental health services. Findings showed improved patient outcomes compared to treatment as usual, which supported the state in scaling the telehealth program to additional rural hospitals to reach more individuals in need of psychiatric services (Cooner, 2018). The IDS creates capacity for agencies to conduct both small- and large- scale research, evaluation, and implementation studies, and to use these data to inform program planning.

\section{Housing First Case Example}

We will now look further into the example of how IS and IDS were applied to the broad scale implementation of Housing First in Charlotte, North Carolina. Housing First is an EBP that "addresses chronic homelessness by providing rapid access to permanent housing without pre-condition of treatment, along with ongoing support services such as crisis intervention, needs assessment, and case management" (The Pew Charitable Trusts, 2021, database line 1244). Housing First permanent supportive housing began in New York, where it was first recognized as an evidence-based practice (Padgett et al., 2016). It has since been implemented throughout the United States and globally, including in Europe (Busch-Geertsema, 2013), Canada (Goering et al., 2014), and Australia (Whittaker et al., 2015).

Housing First Charlotte-Mecklenburg (HFCM) —a crosssector collaborative effort to end chronic homeless-capitalized on the benefits of both IS and IDS to scale and evaluate Housing First at the local level in North Carolina. An earlier pilot study of one local Housing First permanent supportive housing effort demonstrated the initial effectiveness of the program as well as potential utility of multi-sector data to understand implementation and outcomes and convinced broader stakeholders of the promise of the Housing First approach. Between 2015 and 2019, HFCM applied eight implementation strategies, and a team of researchers at the University of North Carolina (UNC) Charlotte recently studied outcomes of this effort (Thomas et al., 2020b).

The research team drew from the framework developed by the At Home/Chez Soi RCT of Housing First permanent supportive housing in Canada. The At Home/Chez Soi team relied on four different implementation frameworks and the broader implementation science literature to develop and test five constructs including Intervention Characteristics, Context of Implementation, Implementation Process, Organizational Characteristics, and Strategies of Implementation (Fleury et al., 2014). HFCM research utilized data and data integration capacity at the ISC (a community IDS housed at the UNC Charlotte Urban Institute discussed previously) to evaluate the implementation and outcomes. Below we further summarize the ways in which IS and IDS concepts were applied.

\section{Implementation Science and Housing First}

\section{Addressing the Role of Context in Implementation}

One of the key lessons highlighted by this study was the importance of situating chronic homelessness within a larger ecosystem. Socioeconomic forces, such as limited affordable housing and economic mobility in the Charlotte-Mecklenburg area, influenced the implementation strategies and ultimate outcomes of the effort to end chronic homelessness by scaling Housing First. An IS lens helped the HFCM research team identify the important contextual factors and suggest modifications to Housing First implementation in response.

\section{Complementing Other Quality and Process Improvement Efforts}

While this study did not explicitly name other process and quality improvement frameworks, the eight implementation strategies included a focus on both incremental, short-term changes as well as theory-driven, long-term changes to homelessness services. For example, creating a registry of all individuals experiencing chronic homelessness (called the "By-Name-List") allowed HFCM to continually monitor progress toward housing these individuals and to measure housing outcomes over five years. Additionally, IS helped the HFCM research team transform process improvement strategies into a robust, mixed methods study with a clear conceptual framework, which was necessary for such a complex policy implementation project.

\section{Furthering the Evidence on Policy Effectiveness and Implementation}

HFCM simultaneously studied implementation and effectiveness outcomes, as key leaders and stakeholders in this effort recognized the importance of understanding both sets of outcomes to inform future work. In terms of effectiveness, the study identified 1011 people on the By-Name-List who became housed in the course of the study and demonstrated high housing retention rates overall. The study also followed 330 people from the By-Name-List up to 24 months and gathered follow-up data on 294 of them-165 of whom were housed and 129 who were not and served as the comparison group on a range of standardized and service utilization measures (Thomas et al., 2020a). On the implementation side, robust fidelity criteria established through research 
(Stefancic et al., 2013) were measured at multiple points in the study, a cost analysis was conducted, and the study looked at the impact of project structure and management on outcomes.

\section{Guiding Systematic De-implementation of Policies and Programs}

While this study did not directly address de-implementation, an IS lens allowed the HFCM research team to identify the importance of de-implementing old ways of thinking about chronic homelessness. Successful implementation of Housing First requires the broader homeless services system to adopt the philosophy that "housing is a foundation and not a reward... and services begin with the person instead of a threshold of eligibility criteria" (Thomas et al., 2020b, p. 3 ). The study findings identify the importance of paying attention to shifting philosophy alongside replacing program procedures in order to maintain fidelity to the EBP.

\section{Integrated Data System and Housing First}

\section{Facilitating Governance Processes for Ethical, Legal Data Access and Use}

Administrative data used in the study came from the Institute for Social Capital (ISC), an IDS housed at the UNC Charlotte Urban Institute. Due to ISC's existing governance structure (i.e., an legally designated board of directors and its data oversight committee that thoroughly reviews and approves data requests and develops data privacy policies), this study was able to legally and ethically access administrative data from the Homeless Management Information System (HMIS) and integrate these data with 10 other health and human services sources (ISC, n.d.; Thomas et al., 2020a). These data ultimately supported the study's mixed methods analysis strategy.

\section{Providing Relevant, High-Quality Data for Efficient Analysis}

Health and human services data were integrated with ByName-List data and data collected through the research project in order to examine characteristics of those served by HFCM throughout the course of the initiative. Access to high-quality integrated data allowed HFCM to understand aggregate trends and outcomes that supplemented data from surveys, interviews, focus groups, observations, and artifacts. Without the IDS, HFCM would not have had robust decision support data. Importantly, ISC was not just a data provider for this study, but also an internal service and planning partner throughout the project. The ongoing, working relationship among IDS partners facilitated efficient analyses that without the services of an IDS, would not have been feasible.

\section{Efficiently Addressing Pressing Research, Evaluation, and Planning Needs}

Growing concerns of chronic homelessness galvanized HFCM partners to develop a cross-system strategy to implement Housing First. While IDS data integration and analysis was just one component of the overall implementation evaluation strategy, having access to readily available, high-quality data enabled more robust analyses of outcomes. Furthermore, the ability to interrogate multiple data sources allowed the HFCM team to pinpoint the need for a more hospitable intervention implementation environment (NIRN, 2021).

\section{Recommendations for Human Service Agencies}

For human service agencies looking to enhance their evidence-based policymaking, we offer two key recommendations to help navigate the use of IS and IDS in complex, realworld environments. First, we recommend drawing upon existing IS frameworks. There are over 100 frameworks to choose from, most of which fit into three overarching categories: process models (guide translation of research to practice), determinant frameworks (organize factors thought to influence implementation), or evaluation models (guide evaluation of the implementation itself) (Nilsen, 2015). Depending on where the agency is in the research process, frameworks can provide structure for thinking through existing knowledge of the social problem and potential EBP implementation strategies (e.g., Proctor et al., 2011), guidance for planning and outlining the IS research study flow (e.g., the EPIS Framework in Moullin et al., 2019), or mapping behavior change theory to implementation strategies (e.g., the COM-B Framework in Michie et al., 2011).

It is important to acknowledge that no framework is perfect and the best-fitting framework will largely depend on agency context. It may be helpful to choose a framework used in a similar IS study or one recommended by a colleague or key player in the implementation effort. Another option is combining applicable components of several frameworks. For additional guidance on choosing and using frameworks see Fixsen et al. (2021), Nilsen (2015), Tabak et al. (2012), the National Collaborating Centre for Methods and Tools (2016), the Implementation Science Resource Hub (n.d), and the Global Implementation Society (2021).

Second, we recommend that agencies looking to establish or strengthen their integrated data capacity start small, demonstrate impact early, and scale up over time. Most IDS efforts start with a single project or social problem that 
motivates a group of stakeholders to share and integrate their data. This creates an opportunity to align priorities for data sharing and gradually establish governance, legal, and technical procedures that meet the needs of all data contributors. Building IDS capacity is challenging and the best path forward largely depends on context-what works for one jurisdiction may not work as well in another. It can be helpful to think of IDS building in stages, where small steps to build trust, negotiate agreements, and conduct simple data sharing projects can create a strong foundation from which to gradually take on more complex projects and onboard new data partners.

We recommend looking for opportunities for quick, impactful wins that can demonstrate the value of IDS and build the necessary trust, buy-in, and resource commitment to improve data capacity and quality. For example, partners could create a cross-agency dashboard to track progress on an important goal or execute an ad hoc data sharing agreement to analyze data between agencies on a timely issue. See Hawn Nelson et al. (2020) for more guidance on how to begin an IDS effort and Zanti et al. (2021) for legislative and funding strategies to build and sustain an IDS. Both pieces are framed for a U.S. audience; however, the general principles shared may be applicable in global contexts.

\section{Conclusion}

Together, the fields of IS and IDS consist of principles and practices that are necessary to advance human service agency capacity for evidence-based policymaking. Specifically, IS can help agencies address the role of context when right-sizing EBPs to the populations they serve. It also complements existing quality and process improvement efforts, offers a hybrid trial method for continuing the study of effectiveness alongside implementation outcomes, and provides guidance for the systematic de-implementation of ineffective policies. On the other hand, the IDS approach offers a governance framework, which is necessary for the ethical and legal use of agency data to further effectiveness and implementation research. Additionally, an IDS can provide relevant, high-quality data that more efficiently address time-sensitive agency needs. The crux of this convergence between IS and IDS, however, is in helping human service agencies deliver the best possible services and outcomes for the communities they serve. As the Housing First CharlotteMecklenburg case suggests, IS and IDS can be leveraged in tandem to enhance evidence-based policymaking in human service agencies.

Acknowledgements The authors would like to acknowledge Dr. Amy Hawn Nelson and Justin Lane for their reviews of this article; Mecklenburg County, North Carolina, Roof Above, and the UNC Charlotte
Urban Institute and College of Health and Human Services for funding the Housing First Charlotte-Mecklenburg study; and, the Institute for Social Capital for providing integrated data for the study.

Author Contributions SZ conceptualized the manuscript and prepared the initial draft. LT is the principal investigator of the Housing First Charlotte-Mecklenburg study, provided case content, and critically revised the manuscript. Both authors contributed to the reviewing and editing of the final manuscript.

Funding The Housing First Charlotte-Mecklenburg study referenced in this manuscript was funded by Mecklenburg County, Roof Above, and UNC Charlotte.

\section{Declarations}

Conflict of interest Author B has received research support from Mecklenburg County.

Ethical Approval The Housing First Charlotte-Mecklenburg study referenced in this article was approved by the UNC Charlotte Institutional Review Board.

\section{References}

Aarons, G. A., Hurlburt, M., \& Horwitz, S. M. (2011). Advancing a conceptual model of evidence-based practice implementation in public service sectors. Administration and Policy in Mental Health and Mental Health Services Research, 38(1), 4-23.

Allison-Jacobs, R. (2018). IDS case study: The Institute for Social Capital: Creating a hybrid IDS model for the greater CharlotteMecklenburg region. Actionable Intelligence for Social Policy. https://www.aisp.upenn.edu/wp-content/uploads/2018/11/ISC. pdf

American Chemical Society International Historic Chemical Landmarks. (n.d.). Discovery and development of Penicillin. http:// www.acs.org/content/acs/en/education/whatischemistry/landm arks/flemingpenicillin.html

Antony, J. (2011). Six Sigma vs Lean. International Journal of Productivity and Performance Management, 60(2), 185-190. https:// doi.org/10.1108/17410401111101494

Baptista, I., Benjaminsen, L., Pleace, N., \& Busch-Geertsema, V. (2017). Family homelessness in Europe: 7 EOH comparative studies in homeless. https://eprints.whiterose.ac.uk/125725/

Baron, J. H. (2009). Sailors' scurvy before and after James Lind-A reassessment. Nutrition Reviews, 67(6), 315-332. https://doi.org/ 10.1111/j.1753-4887.2009.00205.x

Berkowitz, E., Jenkins, D., Culhane, D., Zanti, S., Hawn Nelson, A., \& Burnett, T. (2020). IDS landscape analysis: Models, motivations, and capacity for cross-agency data sharing. University of Pennsylvania, Actionable Intelligence for Social Policy. Unpublished report.

Busch-Geertsema, V. (2013). Housing First Europe: Final report. Bremen/Brussels: European Union Programme for Employment and Social Solidarity. https://www.habitat.hu/files/FinalRepor tHousingFirstEurope.pdf

Centers for Disease Control and Prevention. (2020). Considerations for wearing masks. https://www.cdc.gov/coronavirus/2019-ncov/ prevent-getting-sick/cloth-face-cover-guidance.html?CDC_ AA refVal=https $\% 3 \mathrm{~A} \% 2 \mathrm{~F} \% 2 \mathrm{Fwww} . \mathrm{cdc}$.gov $\% 2 \mathrm{Fcoronavirus} \%$ 2F2019-ncov\%2Fprevent-getting-sick\%2Fcloth-face-cover.html 
CFIR Research Team-Center for Clinical Management Research. (2021). Constructs. Consolidated Framework for Implementation Research. https://cfirguide.org/constructs/

Chege, N., \& Ucembe, S. (2020). Kenya's Over-reliance on institutionalization as a child care and child protection model: A root-cause approach. Social Sciences, 9(4), 57. https://doi.org/ 10.3390/socsci9040057

Childcare.gov. (n.d.). Child care licensing and regulations. U.S. Department of Health and Human Services, Administration for Children and Families. https://www.childcare.gov/index.php/ consumer-education/child-care-licensing-and-regulations

Cooner, S. (2018). SCDMH Emergency Department Telepsychiatry Consultation Program. Rural Health Information Hub. https:// www.ruralhealthinfo.org/project-examples/992

Culhane, D. P., \& Byrne, T. (2010). Ending chronic homelessness: Cost-effective opportunities for interagency collaboration. Penn School of Social Policy and Practice Working Paper. https:// repository.upenn.edu/spp_papers/143/

Curran, G. M., Bauer, M., Mittman, B., Pyne, J. M., \& Stetler, C. (2012). Effectiveness-implementation hybrid designs: Combining elements of clinical effectiveness and implementation research to enhance public health impact. Medical Care, 50(3), 217. https://doi.org/10.1097/MLR.0b013e3182408812

D.A.R.E. America (2021). D.A.R.E. Hometowns-U.S.A. \& International. https://dare.org/where-is-d-a-r-e/

Dearing, J. W., \& Kee, K. F. (2012). Historical roots of dissemination and implementation science. In: Dissemination and implementation research in health: Translating science to practice (pp. 55-71). https://doi.org/10.1097/MLR.0b013e3182408812

Dunn, H. L. (1946). Record linkage. American Journal of Public Health and the Nations Health, 36(12), 1412-1416. https://doi. org/10.2105/AJPH.36.12.1412

Eccles, M. P., \& Mittman, B. S. (2006). Welcome to implementation science. Implementation Science. https://doi.org/10.1186/ 1748-5908-1-1

European Monitoring Centre for Drugs and Addiction. (n.d.). Best practice portal-Evidence database. https://www.emcdda. europa.eu/best-practice/evidence-summaries

Fantuzzo, J., \& Culhane, D. P. (2016). Actionable intelligence: Using integrated data systems to achieve a more effective, efficient, and ethical government. Palgrave Macmillan.

Fantuzzo, J., Henderson, C., Coe, K., \& Culhane, D. (2017). The integrated data system approach: A vehicle to more effective and efficient data-driven solutions in government. Actionable Intelligence for Social Policy, University of Pennsylvania. https:// www.aisp.upenn.edu/resource-article/the-integrated-data-system-approach-a-vehicle-to-more-effective-and-efficient-datadriven-solutions-in-government/

Fives, A., Russell, D. W., Canavan, J., Lyons, R., Eaton, P., Devaney, C., Kearns, N., \& O'Brien, A. (2015). The ethics of randomized controlled trials in social settings: Can social trials be scientifically promising and must there be equipoise? International Journal of Research \& Method in Education, 38(1), 56-71. https://doi.org/10.1080/1743727X.2014.908338

Fixsen, A., Aijaz, M., Fixsen, D.L., Burks, E., \& Schultes, M. (2021). Implementation frameworks: An analysis. Active Implementation Research Network. https://www.activeimplementation.org/ wp-content/uploads/2021/04/AIRN-AFixsen-FrameworksAnaly sis-2021.pdf

Fleury, M. J., Grenier, G., \& Vallée, C. (2014). Evaluation of the implementation of the Montreal At Home/Chez Soi project. BMC Health Services Research, 14, 557. https://doi.org/10. 1186/s12913-014-0557-6

Foundations for Evidence-Based Policymaking Act of 2018, 5 U.S.C. $\S \S 101-311(2018)$
Gibbs, L., Hawn Nelson, A., Dalton, E., Cantor, J., Shipp, S., \& Jenkins, D. (2017). IDS governance: Setting up for ethical and effective use, expert panel report. Actionable Intelligence for Social Policy, University of Pennsylvania. https://www.aisp. upenn.edu/wp-content/uploads/2016/07/Governance.pdf

Glasgow, R. E., Vogt, T. M., \& Boles, S. M. (1999). Evaluating the public health impact of health promotion interventions: The REAIM framework. American Journal of Public Health, 89(9), 1322-1327. https://doi.org/10.2105/AJPH.89.9.1322

Global Implementation Society. (2021). Resource library. https://globa limplementation.org/resources/

Goering, P., Veldhuizen, S., Watson, A., Adair, C., Kopp, B., Latimer, E., \& Aubry, T. (2014). National at home/Chez Soi final report. Calgary, AB: Mental Health Commission of Canada, 48. https:// www.mentalhealthcommission.ca

GPRA Modernization Act of 2010, 31 U.S.C. $\$ \S 1101-1115$ (2010).

Hawn Nelson, A., Jenkins, D., Zanti, S., Katz, M., Burnett, T., Culhane, D., \& Barghaus, K. (2020). Introduction to data sharing and integration. Actionable Intelligence for Social Policy. University of Pennsylvania. https://www.aisp.upenn.edu/wp-content/uploads/ 2020/06/AISP-Intro-.pdf

Implementation Science Resource Hub. (n.d.). Pick a theory, model, or framework. University of Washington. https://impsciuw.org/imple mentation-science/research/frameworks/

Institute for Social Capital. (n.d.) ISC data and research oversight committee. UNC Charlotte Urban Institute. https://ui.uncc.edu/ our-work/institute-social-capital/isc-data-and-research-oversightcommittee

International Population Data Linkage Network. (n.d.). About the international population data linkage network. https://www.ipdln.org

Kay, A. (2011). Evidence-based policy-making: The elusive search for rational public administration. Australian Journal of Public Administration, 70(3), 236-245. https://doi.org/10.1111/j.14678500.2011.00728.x

Kettl, D. F. (2002). The transformation of governance. Johns Hopkins University Press.

Kettl, D. F. (2009). The next government of the United States: Why our institutions fail us and how to fix them. WW Norton \& Company.

Kettl, D. F. (2012). Politics of the administrative process (5th ed.). CQ Press.

Kirchner, J. E., Ritchie, M. J., Pitcock, J. A., Parker, L. E., Curran, G. M., \& Fortney, J. C. (2014). Outcomes of a partnered facilitation strategy to implement primary care-mental health. Journal of General Internal Medicine, 29(4), 904-912. https://doi.org/10. 1007/s11606-014-3027-2

Kirk, M. A., Kelley, C., Yankey, N., Birken, S. A., Abadie, B., \& Damschroder, L. (2015). A systematic review of the use of the consolidated framework for implementation research. Implementation Science, 11(1), 1-13. https://doi.org/10.1186/s13012-016-0437-z

Kitzmiller, E. (2014). The circle of love: South Carolina's IDS case study. Actionable Intelligence for Social Policy, University of Pennsylvania. https://www.aisp.upenn.edu/wp-content/uploads/ 2015/08/SouthCarolina_CaseStudy.pdf

Koczwara, B., Stover, A. M., Davies, L., Davis, M. M., Fleisher, L., Ramanadhan, S., Schroeck, F. R., Zullig, L. L., Chambers, D. A., $\&$ Proctor, E. (2018). Harnessing the synergy between improvement science and implementation science in cancer: A call to action. Journal of Oncology Practice, 14(6), 335. https://doi.org/ 10.1200/JOP.17.00083

Laklija, M., Babić, M. M., \& Cheatham, L. P. (2020). Institutionalization of children with disabilities in Croatia: Social workers' perspectives. Child \& Youth Services, 41(2), 184-203. https://doi. org/10.1080/0145935X.2020.1752170

Lane-Fall, M. B., Curran, G. M., \& Beidas, R. S. (2019). Scoping implementation science for the beginner: Locating yourself on the "subway line" of translational research. BMC Medical 
Research Methodology, 19(1), 133. https://doi.org/10.1186/ s12874-019-0783-z

Lindblom, C. E., \& Cohen, D. K. (1979). Usable knowledge: Social science and social problem solving (Vol. 21). Yale University Press. Marr, M. D. (2015). Better must come. Cornell University Press.

May, C., Finch, T., Mair, F., Ballini, L., Dowrick, C., Eccles, M., Gask, L., MacFarlane, A., Murray, E., Rapley, T., Rogers, A., Treweek, S., Wallace, P., Anderson, G., Burns, J., \& Heaven, B. (2007). Understanding the implementation of complex interventions in health care: The normalization process model. BMC Health Services Research, 7(1), 1-7. https://doi.org/10.1186/ 1472-6963-7-148

McKay, V. R., Morshed, A. B., Brownson, R. C., Proctor, E. K., \& Prusaczyk, B. (2018). Letting go: Conceptualizing intervention de-implementation in public health and social service settings. American Journal of Community Psychology, 62(1-2), 189-202. https://doi.org/10.1002/ajcp.12258

Michie, S., Van Stralen, M. M., \& West, R. (2011). The behaviour change wheel: A new method for characterising and designing behaviour change interventions. Implementation Science, 6(1), 1-12. https://doi.org/10.1186/1748-5908-6-42

Moullin, J. C., Dickson, K. S., Stadnick, N. A., Rabin, B., \& Aarons, G. A. (2019). Systematic review of the exploration, preparation, implementation, sustainment (EPIS) framework. Implementation Science, 14(1), 1-16. https://doi.org/10.1186/s13012-018-0842-6

National Association of Counties. (2020). 2020 NACo policy priorities. https://www.naco.org/resources/featured/2020-naco-policy-prior ities

National Collaborating Centre for Methods and Tools. (2016). Implementation frameworks, theories and models: An interactive site for practitioners and researchers. McMaster University. http:// www.nccmt.ca/resources/search/254

National Implementation Research Network. (n.d.). Module 2: Implementation drivers. https://nirn.fpg.unc.edu/module-2/implementa tion-drivers

National Institute on Drug Abuse. (2020). Opioid overdose crisis. https://www.drugabuse.gov/drug-topics/opioids/opioid-overd ose-crisis

Nilsen, P. (2015). Making sense of implementation theories, models and frameworks. Implementation Science, 10(1), 1-13. https://doi. org/10.1186/s13012-015-0242-0

Norton, W. E., Chambers, D. A., \& Kramer, B. S. (2019). Conceptualizing de-implementation in cancer care delivery. Journal of Clinical Oncology, 37(2), 93-96. https://doi.org/10.1200/JCO. 18.00589

Nutley, S. M., Walter, I., \& Davies, H. T. (2007). Using evidence: How research can inform public services. Policy Press.

Padgett, D., Henwood, B. F., Tsemberis, S., \& Tsemberis, S. J. (2016). Housing first: Ending homelessness, transforming systems, and changing lives. Oxford University Press.

The Pew Charitable Trusts. (2021). Results first clearinghouse database. https://www.pewtrusts.org/en/research-and-analysis/datavisualizations/2015/results-first-clearinghouse-database

Pew-MacArthur Results First Initiative. (2014). Evidence-based policymaking: A guide for effective government. http://www.pewtrusts. org/ /media/assets/2014/11/evidencebasedpolicymakingaguid eforeffectivegovernment.pdf

Proctor, E., Silmere, H., Raghavan, R., Hovmand, P., Aarons, G., Bunger, A., Griffey, R., \& Hensley, M. (2011). Outcomes for implementation research: Conceptual distinctions, measurement challenges, and research agenda. Administration and Policy in Mental Health and Mental Health Services Research, 38(2), 65-76. https://doi.org/10.1007/s10488-010-0319-7

Prusaczyk, B., Swindle, T., \& Curran, G. (2020). Defining and conceptualizing outcomes for de-implementation: Key distinctions from implementation outcomes. Implementation Science Communications, 1, 1-10. https://doi.org/10.1186/s43058-020-00035-3

Public Health Agency of Canada. (n.d.). Canadian best practices portal. https://cbpp-pcpe.phac-aspc.gc.ca/interventions/search-inter ventions/

Rohe, W. M. (2017). Tackling the housing affordability crisis. Housing Policy Debate, 27(3), 490-494. https://doi.org/10.1080/10511482. 2017.1298214

Sanderson, I. (2002). Evaluation, policy learning and evidence-based policy making. Public Administration, 80(1), 1-22. https://doi. org/10.1111/1467-9299.00292

Shea, C. M., Turner, K., Albritton, J., \& Reiter, K. L. (2018). Contextual factors that influence quality improvement implementation in primary care: The role of organizations, teams, and individuals. Health Care Management Review, 43(3), 261. https://doi.org/10. 1097/HMR.0000000000000194

State Data Sharing Initiative. (2018). Data sharing toolkit. The Center for Regional Economic Competitiveness. http://www.statedatas haring.org/data-sharing/\#toolkit

Stefancic, A., Tsemberis, S., Messeri, P., Drake, R., \& Goering, P. (2013). The Pathways Housing First fidelity scale for individuals with psychiatric disabilities. American Journal of Psychiatric Rehabilitation, 16(4), 240-261. https://doi.org/10.1080/15487768. 2013.847741

Tabak, R. G., Khoong, E. C., Chambers, D. A., \& Brownson, R. C. (2012). Bridging research and practice: Models for dissemination and implementation research. American Journal of Preventive Medicine, 43(3), 337-350. https://doi.org/10.1016/j.amepre. 2012.05.024

Taylor, A. (2020). How the split over masks sums up America's chaotic coronavirus response. The Washington Post. https://www.washi ngtonpost.com/world/2020/06/25/face-masks-america-divided/

The California Evidence-Based Clearinghouse for Child Welfare. (n.d.). CEBC overview. https://www.cebc4cw.org/

Thomas, M.L., Hutchison, J., Lane, J., Carman, J., Schulkind, L., \& Vercruysse, C. (2020a). Housing First Charlotte-Mecklenburg Research \& Evaluation Project: Outcomes \& service utilization final report. https://ui.uncc.edu/sites/ui.uncc.edu/files/media/ HFCM\%20Final\%20Outcomes\%20Report\%202020-Final.pdf

Thomas, M.L., Hutchison, J., Lane, J., Carman, J., Schulkind, L., \& Vercruysse, C. (2020b). Housing First Charlotte-Mecklenburg Research \& Evaluation Project: Process evaluation final report. University of North Carolina at Charlotte. https://ui.uncc.edu/ sites/ui.uncc.edu/files/media/V3HFCM\%20Final\%20Process\% 20Evaluation\%20Report\%202020-Final\%209-2-20v3.pdf

Title IV-E Prevention Services Clearinghouse. (n.d.). Description. https://preventionservices.abtsites.com/

Whittaker, E., Swift, W., Flatau, P., Dobbins, T., Schollar-Root, O., \& Burns, L. (2015). A place to call home: Study protocol for a longitudinal, mixed methods evaluation of two housing first adaptations in Sydney, Australia. BMC Public Health, 15(1), 1-9. https://doi. org/10.1186/s12889-015-1700-y

World Health Organization. (2020). Opioid overdose. https://www. who.int/news-room/fact-sheets/detail/opioid-overdose

Wulczyn, F., Alpert, L., Martinez, Z., \& Weiss, A. (2015). Within and between state variation in the use of congregate care. The Center for State Child Welfare Data, Chapin Hall at theUniversity of Chicago. https://fcda.chapinhall.org/wp-content/uploads/2015/07/ Congregate-Care_webcopy.pdf

Zanti, S., Jenkins, D., Berkowitz, E., Hawn Nelson, A., Burnett, T., $\&$ Culhane, D. (2021). Building and sustaining state data integration efforts: Legislation, funding, and strategies. Actionable Intelligence for Social Policy. University of Pennsylvania. https:// www.aisp.upenn.edu/resource-article/building-sustaining-statedata-integration-efforts-legislation-funding-and-strategies/ 